\title{
Digestibilidade Ileal Aparente e Verdadeira de Aminoácidos de Farinhas de Carne e Ossos para Suínos ${ }^{1}$
}

\author{
Paulo Cesar Pozza², Paulo Cezar Gomes ${ }^{3}$, Juarez Lopes Donzele ${ }^{3}$, Horacio Santiago \\ Rostagno ${ }^{3}$, Magali Soares dos Santos Pozza ${ }^{2}$, Eduardo Terra Nogueira ${ }^{4}$
}

\begin{abstract}
RESUMO - O experimento foi conduzido com o objetivo de determinar a digestibilidade ileal aparente e verdadeira dos aminoácidos de seis diferentes farinhas de carne e ossos. Foram utilizados 12 suínos mestiços, machos castrados, com peso médio inicial de 52,5 $\pm 5,1 \mathrm{~kg}$. Os animais foram previamente submetidos à cirurgia para implantação de cânula "T" simples no íleo terminal, e, após 20 dias de recuperação, foram distribuídos em um delineamento experimental de blocos ao acaso, com seis tratamentos, quatro repetições e um animal por unidade experimental. Ao término das duas primeiras repetições, os tratamentos foram redistribuídos para evitar que o mesmo animal recebesse a mesma dieta em duas repetições consecutivas. Os tratamentos consistiram de uma dieta isenta de proteína à base de açúcar, amido, óleo e casca de arroz, tendo como única fonte protéica as farinhas de carne e ossos. Os coeficientes de digestibilidade ileal aparente da lisina, treonina e metionina, das diferentes farinhas de carne e ossos variaram de 54,87 a 74,80; 62,62 a 81,19 e 72,35 a $85,46 \%$, respectivamente, e a variação entre os coeficientes de digestibilidade ileal verdadeira foram de 57,00 a 76,08; 66,26 a 83,07 e 73,76 a $86,39 \%$, respectivamente, para a lisina, treonina e metionina. As farinhas de carne e ossos apresentaram grande variação, em função das diferentes amostras, quanto aos coeficientes de digestibilidade ileal aparentes e verdadeiros dos aminoácidos.
\end{abstract}

Palavras-chave: aminoácidos, digestibilidade ileal, farinha de carne e ossos, suínos

\section{Apparent and True Ileal Digestibility of Meat and Bone Meals Amino Acids for Swine}

\begin{abstract}
The experiment was carried out to determine the apparent and true ileal digestibility of amino acids from six different meat and bone meals. Twelvecrossbred swines, castrated males, averaging $52.5 \pm 5.1 \mathrm{~kg}$ initial weight, were used. The animals were previously submitted to the simple $\mathrm{T}$ canula surgery implantation at the terminal ileum and, after twenty days of recovery period, they were allotted to a randomized blocks design, with six treatments, four replicates and one animal per experimental unit. At the end of the first two replicates, the treatments were assigned again to avoid that the same animal received the same diet in two serial replicates. The treatments consisted in a free protein diet based on sugar, starch, vegetable oil and rice peel, with the meat and bone meal as the only protein source. The apparent ileal digestibility coefficients of lysine, threonine and methionine, of the different meat and bone meals, ranged from 54.87 to $74.80 ; 62.62$ to 81.19 and 72.35 to $85.46 \%$, respectively, and the variation among the true ileal digestibility coefficients were from 57.00 to $76.08,66.26$ to 83.07 , and 73.76 to $86.39 \%$, respectively, for lysine, threonine and methionine. The meat and bone meals showed a great variation in function of the different batches, concerning the apparent and true coefficients of amino acid ileal digestibility.
\end{abstract}

Key Words: amino acids, ileal digestibility, meat and bone meal, swines

\section{Introdução}

Para que haja maior precisão na formulação de dietas para suínos, é necessário que se conheçam adequadamente as exigências para cada fase de criação, assim como o valor nutricional dos ingredientes utilizados, uma vez que a maior precisão na formulação e no balanceamento das rações pode reduzir os gastos com alimentação, melhorando sua eficiência e resultando em um produto final de menor custo e melhor qualidade (Albino \& Silva, 1996).
Entre os ingredientes disponíveis, para utilização em dietas de suínos, encontram-se os subprodutos de abatedouros, pois, segundo Vieites (2000), atualmente milhões de toneladas de subprodutos animais são produzidos pelas indústrias. Esses subprodutos precisam ser processados adequadamente para evitar perda econômica, para os setores industriais da cadeia de carnes, e danos ao meio ambiente.

Entre os subprodutos de abatedouros encontra-se a farinha de carne e ossos, que possui elevado conteúdo protéico, entretanto, os valores obtidos na

\footnotetext{
1 Parte da Dissertação de Doutorado do primeiro autor financiada pela FAPEMIG.

2 Professor do curso de Zootecnia/UNIOESTE. E.mail: pcpozza@hotmail.com

3 Professor do Departamento de Zootecnia/UFV.

4 Estudante de Doutorado do Departamento de Zootecnia/UFV
} 
literatura mostram grande variabilidade no conteúdo protéico e na composição aminoacídica deste subproduto. Segundo Knabe et al. (1989), esta variabilidade pode ser resultado de diferenças entre os materiais que compõem as farinhas, do método de processamento utilizado ou da combinação entre ambos.

Em razão dessa variabilidade, torna-se necessário o conhecimento adequado do conteúdo de aminoácidos destes ingredientes. Entretanto, segundo Laplace (1986), é necessário conhecer a quantidade de aminoácidos presentes nos alimentos, como também sua biodisponibilidade para os suínos. Portanto, o valor mais adequado de digestibilidade de aminoácidos dos alimentos parece ser o obtido pela análise de amostras coletadas no íleo terminal, em decorrência da eliminação dos efeitos da flora microbiana do intestino grosso. Assim, os valores de digestibilidade obtidos com amostras coletadas no final do íleo proporcionam a obtenção de coeficientes de digestibilidade ileal aparente. Além disso, pode-se considerar a contribuição de aminoácidos endógenos, o que proporcionaria valores de digestibilidade ileal verdadeira e, conseqüentemente, maior aproximação dos aminoácidos utilizados pelos suínos. Sauer \& Ozimek (1986) relataram que, com o uso de suplementos protéicos, como farinha de carne e ossos, na formulação de rações, a utilização dos valores de aminoácidos digestíveis proporciona maior precisão na formulação.

Objetivou-se, com este trabalho, determinar os valores de aminoácidos digestíveis aparentes e verdadeiros de diferentes partidas de farinhas de carne e ossos para suínos, utilizando a coleta de digesta com cânula simples $\mathrm{T}$.

\section{Material e Métodos}

O experimento foi conduzido no Setor de Suinocultura do Departamento de Zootecnia da Universidade Federal de Viçosa. Foram utilizados 12 suínos mestiços (Landrace x Large White), machos e castrados. Os animais foram submetidos à cirurgia para implantação de cânula "T" simples, conforme método descrito por Bellaver (1989). Após a cirurgia, os animais passaram por 20 dias de recuperação. Durante este período, os animais foram alojados em baias de creche, metálicas, suspensas, com pisos plásticos, laterais teladas, dotadas de comedouros semi-automáticos e bebedouros tipo chupeta, localizadas em prédio de alvenaria com piso de concreto, teto de madeira e com janelas basculantes nas laterais.

Após 20 dias de recuperação, os animais com peso médio inicial de $52,5 \pm 5,1 \mathrm{~kg}$ foram submetidos aos tratamentos e permaneceram durante todo o período experimental nas mesmas baias onde estavam alojados durante o período de recuperação. No interior das instalações, foi utilizado um termômetro de mínima e máxima, à meia altura dos animais, para que fossem realizadas, duas vezes ao dia, as mensurações das respectivas temperaturas durante o período experimental.

O delineamento experimental foi o de blocos ao acaso no tempo, com seis tratamentos e quatro repetições. Ao término das duas primeiras repetições, os tratamentos foram redistribuídos para evitar que o mesmo animal recebesse a mesma dieta em duas repetições consecutivas.

$\mathrm{Na}$ formulação das rações, foram utilizados os valores de composição química e energia digestível, das diferentes farinhas de carne e ossos, obtidos previamente por Pozza (2001) e apresentados na Tabela 1.

Os tratamentos constaram de seis rações isoprotéicas (Tabela 2), formuladas à base de amido de milho, açúcar, casca de arroz, minerais, vitaminas e seis diferentes partidas de farinhas de carne e ossos (FCO1, FCO2, FCO3, FCO4, FCO5 e FCO6).

A casca de arroz foi utilizada para que os tratamentos apresentassem 2,00\% de fibra bruta, sendo previamente separada dos grãos de arroz quebrados, dos remanescentes ainda dentro da casca e das impurezas contidas na palha, por meio de ventilador. As rações experimentais continham $0,5 \%$ de óxido crômico $\left(\mathrm{Cr}_{2} \mathrm{O}_{3}\right)$, utilizado como indicador na determinação da digestibilidade. A quantidade de ração fornecida diariamente a cada animal foi calculada com base no tamanho metabólico $\left(\mathrm{kg}^{0,75}\right)$. Para evitar perdas e facilitar a ingestão, as rações foram umedecidas na proporção de 1:0,75 (peso/volume), fornecidas duas vezes ao dia (7 e $19 \mathrm{~h}$ ).

Foi adotado um período de cinco dias de adaptação aos tratamentos e um dia de coleta, ressaltando-se que as coletas tiveram início às $7 \mathrm{~h}$ e término às $7 \mathrm{~h}$ do dia seguinte, realizadas em intervalos de três horas.

As amostras de digesta foram coletadas em sacos de polietileno, presos à cânula e, posteriormente, colocadas em sacos plásticos, identificadas e armazenadas em congelador $\left(-5^{\circ} \mathrm{C}\right)$, até o final do período de coleta. Ao final desse período, as amostras com-

\section{R. Bras. Zootec., v.33, n.5, p.1181-1191, 2004}


postas por animal foram descongeladas, pesadas, homogeneizadas e liofilizadas.

As análises laboratorais foram realizadas no Laboratório de Nutrição Animal do Departamento de Zootecnia da Universidade Federal de Viçosa. Foram determinados os teores de matéria seca, proteína bruta e cromo das digestas e rações experimentais, segundo técnicas descritas por Silva (1990).

A composição em aminoácidos das digestas e dos alimentos foi realizada no Laboratório de Nutrição Animal do Departamento de Zootecnia da Universidade Federal de Viçosa e na Ajinomoto Biolatina Ind. e Com. Ltda., por meio de cromatografia de troca iônica.

Para determinar dos valores de digestibilidade ileal verdadeira, foram utilizados os valores de perdas endógenas dos aminoácidos, obtidos por Pozza (2001), que utilizou uma dieta isenta de proteína com $2 \%$ de fibra bruta, determinada nas mesmas instalações, sob as mesmas condições em que foram determinados os valores de digestibilidade ileal aparente das farinhas de carne e ossos.

A digestibilidade ileal dos aminoácidos foi calculada com base nos níveis de cromo (Cr), nas rações e fezes dos suínos, por meio do cálculo do fator de indigestibilidade. Para determinar os coeficientes de digestibilidade aparente e verdadeira dos aminoácidos, foram utilizadas as fórmulas descritas por Rostagno \& Featherston (1977). Utilizou-se o teste de comparação de médias Student Newman-Keuls, em nível de $5 \%$ de probabilidade, entre os valores médios dos coeficientes de digestibilidade aparente e verdadeira dos aminoácidos, por intermédio do Sistema de Análises Estatísticas e Genéticas - SAEG (UFV, 1999).

\section{Resultados e Discussão}

A composição em aminoácidos totais das diferentes partidas das farinhas de carne e ossos está apresentada na Tabela 3. Pode-se observar alta variabilidade do conteúdo protéico e, conseqüentemente, de aminoácidos totais das farinhas de carne e ossos, com valores de proteína bruta entre 33,53 e $52,43 \%$ e de lisina, entre 1,42 e 2,36\%, verificando-se aumento no conteúdo dos demais aminoácidos, em função dos maiores níveis de proteína bruta das diferentes farinhas de carne e ossos. Esta variação pode ser observada também no trabalho desenvolvido por Rostagno et al. (2000), que relataram conteúdo de lisina total de 1,74 a $3,10 \%$, com teor de proteína bruta de 35,96 a $61,23 \%$, respectivamente.

A mesma relação é apresentada pelo Ministério da Agricultura da Pecuária e Abastecimento - MAPA (1996), que obteve a lisina total variando de 2,10 a $2,19 \%$, relativo a 40 e $50 \%$ de proteína bruta.

A variabilidade observada no conteúdo protéico e de aminoácidos pode ser atribuída a diferenças na matéria-prima utilizada. Segundo Berk \& Schulz (1995), na comparação dos conteúdos de proteína e de aminoácidos de diferentes farinhas de carne e ossos, deve-se considerar a composição do alimento, em relação à matéria-prima utilizada. Seerley (1991) relatou que a qualidade da farinha de carne e ossos é dependente, entre outros fatores, da quantidade de ossos e de tecido tendinoso. A variação entre o conteúdo de proteína bruta e aminoácidos está inversamente relacionada ao conteúdo de matéria mineral da farinha de carne e ossos (Johnson et al., 1998).

Tabela 1 - Composição química e energética das diferentes farinhas de carne e ossos (FCO), expressos na matéria natural ${ }^{1,2}$

Table 1 - Chemical and energy composition of the different meat and bone meals (MBM), as fed basis ${ }^{1,2}$

\begin{tabular}{lccccc}
\hline FCO & ED $(\mathrm{kcal} / \mathrm{kg})$ & $\mathrm{PB}(\%)$ & $\mathrm{EE}(\%)$ & $\mathrm{Ca}(\%)$ & $\mathrm{PT}(\%)$ \\
$M B M$ & $D E(\mathrm{kcal} / \mathrm{kg})$ & $C P(\%)$ & $E E(\%)$ & & $T P(\%)$ \\
\hline FCO 1 $(M B M 1)$ & 1717 & 33,53 & 14,71 & 15,49 & 8,18 \\
FCO 2 $(M B M 2)$ & 1897 & 35,72 & 12,62 & 15,91 & 8,81 \\
FCO 3 $($ MBM 3) & 1932 & 37,94 & 11,51 & 15,33 & 8,52 \\
FCO 4 $(M B M 4)$ & 2056 & 40,26 & 11,71 & 15,02 & 7,92 \\
FCO 5 $($ MBM 5) & 2245 & 40,50 & 10,46 & 14,58 & 7,25 \\
FCO 6 $($ MBM 6) & 2908 & 52,43 & 12,88 & 9,04 & 5,63 \\
\hline
\end{tabular}

${ }^{1}$ Análises realizadas no Laboratório de Nutrição Animal do Departamento de Zootecnia da Universidade Federal de Viçosa.

${ }_{1}$ Analyses were performed at the Animal Nutrition Laboratory of the Animal Science Department of the Universidade Federal de Viçosa.

$2 \mathrm{ED}=$ energia digestível; $\mathrm{PB}=$ proteína bruta; $\mathrm{EE}=$ extrato etéreo; $\mathrm{MM}=$ matéria mineral, Ca = cálcio; $\mathrm{PT}=$ fósforo total.

$2 D E=$ digestible energy $; C P=$ crude protein, $E E=$ ether extract $; C a=$ calcium; $T P=$ total phosphorus.

R. Bras. Zootec., v.33, n.5, p.1181-1191, 2004 
Tabela 2 - Composição centesimal das rações experimentais Table 2 - Centesimal composition of the experimental diets

\begin{tabular}{|c|c|c|c|c|c|c|}
\hline \multirow{3}{*}{$\begin{array}{l}\text { Ingredientes } \\
\text { Ingredients }\end{array}$} & \multicolumn{6}{|c|}{$\begin{array}{l}\text { Tratamentos } \\
\text { Treatments }\end{array}$} \\
\hline & FCO1 & $\mathrm{FCO} 2$ & $\mathrm{FCO} 3$ & $\mathrm{FCO} 4$ & FCO5 & FCO6 \\
\hline & & & & & & \\
\hline $\begin{array}{l}\text { Farinha de carne e ossos } \\
\text { Meat and bone meal } 1,2\end{array}$ & 34,27 & 32,17 & 30,29 & 28,55 & 28,38 & 21,92 \\
\hline $\begin{array}{l}\text { Casca de arroz } \\
\text { Rice husks }{ }^{1}\end{array}$ & 4,14 & 4,81 & 4,76 & 4,81 & 4,88 & 4,55 \\
\hline $\begin{array}{l}\text { Açúcar }{ }^{3} \\
\text { Sugar }\end{array}$ & 10,00 & 10,00 & 10,00 & 10,00 & 10,00 & 10,00 \\
\hline $\begin{array}{l}\text { Amido }^{3} \\
\text { Starch }^{3}\end{array}$ & 49,48 & 50,91 & 52,84 & 54,53 & 54,63 & 61,42 \\
\hline $\begin{array}{l}\text { Óleo }^{3} \\
\mathrm{Oil}^{3}\end{array}$ & 1,00 & 1,00 & 1,00 & 1,00 & 1,00 & 1,00 \\
\hline Sal & 0,35 & 0,35 & 0,35 & 0,35 & 0,35 & 0,35 \\
\hline $\begin{array}{l}\text { Salt } \\
\text { Suplemento mineral } \\
\text { Mineral supplement }^{4}\end{array}$ & 0,10 & 0,10 & 0,10 & 0,10 & 0,10 & 0,10 \\
\hline $\begin{array}{l}\text { Suplemento vitamínico } \\
\text { Vitamin supplement }^{5}\end{array}$ & 0,05 & 0,05 & 0,05 & 0,05 & 0,05 & 0,05 \\
\hline $\begin{array}{l}\text { Antibiótico } 6 \\
\text { Antibiotic }^{6}\end{array}$ & 0,10 & 0,10 & 0,10 & 0,10 & 0,10 & 0,10 \\
\hline $\begin{array}{l}\text { Antioxidante } \\
\text { Antioxidant }^{7}\end{array}$ & 0,01 & 0,01 & 0,01 & 0,01 & 0,01 & 0,01 \\
\hline $\begin{array}{l}\text { Óxido crômico } \\
\text { Chromic oxide }\end{array}$ & 0,50 & 0,50 & 0,50 & 0,50 & 0,50 & 0,50 \\
\hline $\begin{array}{l}\text { Composição calculada } \\
\text { Calculated composition } \\
\end{array}$ & & & & & & \\
\hline $\begin{array}{l}\text { Matéria seca }(\%) \\
\text { Dry matter }(\%)\end{array}$ & 89,39 & 90,28 & 89,85 & 89,80 & 89,20 & 88,93 \\
\hline $\begin{array}{l}\text { Energia digestível }(\mathrm{kcal} / \mathrm{kg}) \\
\text { Digestible energy }(\mathrm{kcal} / \mathrm{kg})\end{array}$ & 2.915 & 2.990 & 3.036 & 3.098 & 3.155 & 3.407 \\
\hline $\begin{array}{l}\text { Proteína bruta }(\%) \\
\text { Crude protein }(\%)\end{array}$ & 11,50 & 11,50 & 11,50 & 11,50 & 11,50 & 11,50 \\
\hline $\begin{array}{l}\text { Fibra bruta }(\%) \\
\text { Crude fiber }(\%)\end{array}$ & 2,00 & 2,00 & 2,00 & 2,00 & 2,00 & 2,00 \\
\hline $\begin{array}{l}\text { Cálcio }(\%) \\
\text { Calcium }(\%)\end{array}$ & 5,31 & 5,12 & 4,65 & 4,29 & 4,14 & 1,985 \\
\hline $\begin{array}{l}\text { Fósforo (\%) } \\
\text { Phosphorus (\%) }\end{array}$ & 2,809 & 2,84 & 2,59 & 2,27 & 2,06 & 1,24 \\
\hline $\begin{array}{l}1 \text { Valores de composição químiç } \\
\text { Silva (1990). } \\
1 \text { Chemical composition values analy } \\
2 \text { Valores de energia digestível } \\
2 \text { Digestible energy values determine } \\
3 \text { Valores de composição química } \\
\text { et al., 1991). } \\
3 \text { Chemical composition values obtai } \\
{ }^{4} \text { Conteúdo/kg (Content/kg): ferro (ir } \\
1,5 \mathrm{~g} \text {; e veículo q.s.p. (q.s.p. ve } \\
5 \text { Conteúdo/kg (Content/kg): vit. } \\
\text { vit } \mathrm{B}_{12}-30.000 \text { mcg; ácido nico } \\
\text { fólico (folic acid), } 800 \mathrm{mg} \text {; biotin } \\
6 \text { Bacitracina de zinco 15\% (Zinc } \\
{ }^{7} \text { BHT. }\end{array}$ & $\begin{array}{l}\text { Laboratór } \\
\text { FV Animal } \\
\text { or Pozza } \\
\text { belas Bra } \\
\text { Brasileiras } \\
\text { (copper), } 1 \\
\text { I.; vit } \mathrm{D}_{3} \text {, } \\
\text { cid) } 30.00 \\
\text { g; selênio }\end{array}$ & $\begin{array}{l}\text { Jutrição } \\
\text { Laboratc } \\
\text { de Com! } \\
\text { nposição o } \\
\text { alto (coba } \\
.000 \text { U.I.; } \\
\text { ácido pa } \\
\text { ium) } 300\end{array}$ & $\begin{array}{l}\text { do DZO } \\
\text { ording to } \\
\text { o de Alin } \\
\text { entos e Ex } \\
\text { mangané } \\
30.000 \\
\text { ico (pant } \\
\text { veículo }\end{array}$ & $\begin{array}{l}\text { le acordc } \\
\text { lod descri } \\
\text { e Exigên } \\
\text { s de Aves } \\
\text { ganese), } 4 \\
\text { t } \mathrm{B}_{1}-2,( \\
\text { acid), } 12 \text {. } \\
\text { q.s.p. veh }\end{array}$ & $\begin{array}{l}\text { a metodo } \\
\text { Silva (199 } \\
\text { Aves e } \\
\text { s (Rostag } \\
\text { co (zinc), } \\
\mathrm{B}_{2}-5,0 \\
\text { g; Vit. K } \\
.000 \mathrm{~g} \text {. }\end{array}$ & $\begin{array}{l}\text { lescrita por } \\
\text { (Rostagno } \\
\text { l., 1991). } \\
\text { odo (iodine), } \\
\text { B }_{6}-3,0 \text { g; } \\
0 \text { mg; ácido }\end{array}$ \\
\hline
\end{tabular}


Segundo Parsons et al. (1997), o conteúdo de cinzas da farinha de carne e ossos é bom indicador da qualidade protéica, em decorrência de seu reflexo sobre o conteúdo de ossos e colágeno.

A farinha de carne e ossos 6 apresentou perfil de aminoácidos superior ao das demais e valores de lisina, metionina e treonina total semelhantes aos mostrados por Rhône-Poulenc (1993), para farinha de carne e ossos com $50,00 \%$ de proteína bruta, apresentando 2,42;0,58 e 1,61\% para a lisina, metionina e treonina, respectivamente. No entanto, Rostagno et al. (2000) encontraram valores superiores de lisina e metionina, 2,57 e $0,70 \%$, respectivamente, e semelhantes para a treonina $(1,55 \%)$, para a farinha de carne e ossos com 50,00\%. Comparações semelhantes foram feitas para os valores obtidos por Afz et al. (2000), para farinha de carne e ossos com 51,10\% de proteína bruta, que apresentaram valores superiores para a lisina e metionina $(2,51$ e $0,68 \%)$ e semelhantes para a treonina $(1,56 \%)$.

A grande variação entre o conteúdo de aminoácidos de diferentes amostras de farinha de carne e ossos foi também observada por Knabe et al. (1989), que determinaram a digestibilidade ileal aparente de aminoácidos, para suínos, de 12 diferentes alimentos. Esses autores observaram maior variação do conteúdo de nitrogênio e aminoácidos totais, entre as amostras do mesmo alimento, para a farinha de carne e ossos. Obteve-se maior diferença para o triptofano (30\%), e a variação no conteúdo de nutrientes foi atribuída às diferenças entre as proporções de ossos, tecidos moles, sangue e pêlos na matériaprimautilizada.

As farinhas de carne e ossos 4 e 5 apresentaram valores de lisina, metionina e treonina semelhantes aos propostos por Rostagno et al. (2000), para a farinha de carne e ossos, com $40,00 \%$ de proteína bruta, ao passo que as farinhas de carne e ossos 2 e 3 , conteúdos de lisina, metionina e treonina próximos aos propostos por esses autores, para farinha de carne e ossos com $36,00 \%$ de proteína bruta.

As temperaturas máxima e mínima do interior das instalações, durante a condução do ensaio de digestibilidade, foram de $25,7 \pm 1,18$ e $21,1 \pm 1,32^{\circ} \mathrm{C}$, respectivamente.

Os coeficientes de digestibilidade ileal aparente dos aminoácidos das diferentes partidas de farinhas de carne e ossos são apresentados na Tabela 4.

Os maiores coeficientes foram obtidos para a farinha de carne e ossos 6 , que apresentou maiores conteúdos de proteína bruta $(52,43 \%)$ e de aminoácidos totais. Os coeficientes de digestibilidade

Tabela 3 - Composição em aminoácidos totais e proteína bruta (PB) das farinhas de carne e ossos, em porcentagem da matéria natural ${ }^{1}$

Table 3 - Total amino acid and crude protein (CP) composition of the meat and bone meals, as fed basis

\begin{tabular}{|c|c|c|c|c|c|c|}
\hline & \multicolumn{6}{|c|}{$\begin{array}{c}\text { Farinhas de carne e ossos } \\
\text { Meat and bone meals }\end{array}$} \\
\hline & 1 & 2 & 3 & 4 & 5 & 6 \\
\hline $\mathrm{PB}(C P)$ & 33,53 & 35,72 & 37,94 & 40,26 & 40,50 & 52,43 \\
\hline Lisina (Lysine) & 1,419 & 1,675 & 1,677 & 1,990 & 2,008 & 2,362 \\
\hline Metionina (Methionine) & 0,403 & 0,507 & 0,463 & 0,481 & 0,554 & 0,612 \\
\hline Treonina (Threonine) & 0,815 & 0,992 & 0,978 & 1,095 & 1,230 & 1,574 \\
\hline Arginina (Arginine) & 2,519 & 2,836 & 2,818 & 3,204 & 3,110 & 3,722 \\
\hline Histidina (Histidine) & 0,396 & 0,574 & 0,463 & 0,547 & 0,635 & 0,897 \\
\hline Valina(Valine) & 1,106 & 1,342 & 1,301 & 1,441 & 1,617 & 1,906 \\
\hline Isoleucina (Isoleucine) & 0,681 & 0,784 & 0,793 & 0,988 & 0,943 & 1,241 \\
\hline Leucina (Leucine) & 1,481 & 1,738 & 1,718 & 2,006 & 2,109 & 2,763 \\
\hline Fenilalanina (Phenylalanine) & 0,907 & 1,036 & 1,039 & 1,102 & 1,249 & 1,564 \\
\hline Cistina (Cystine) & 0,146 & 0,198 & 0,200 & 0,167 & 0,225 & 0,380 \\
\hline Alanina (Alanine) & 2,789 & 3,107 & 3,046 & 3,265 & 3,344 & 3,866 \\
\hline Ác. aspártico (Aspartic acid) & 2,106 & 2,425 & 2,438 & 2,702 & 2,828 & 3,506 \\
\hline Ac. glutâmico (Glutamic acid) & 3,538 & 4,003 & 4,101 & 4,162 & 4,565 & 6,038 \\
\hline Glicina (Glycine) & 6,056 & 6,322 & 6,490 & 7,072 & 6,500 & 7,393 \\
\hline Serina (Serine) & 1,193 & 1,288 & 1,394 & 1,425 & 1,579 & 1,892 \\
\hline Tirosina (Tyrosine) & 0,369 & 0,453 & 0,474 & 0,467 & 0,613 & 0,792 \\
\hline
\end{tabular}

${ }^{1}$ Análises realizadas no Laboratório de Nutrição Animal (DZO - UFV), e Ajinomoto Ind. e Com. Ltda.

${ }^{1}$ Analyses were performed at the Animal Nutrition Laboratory (DZO - UFV), and Ajinomoto Ind. and Com. Ltda.

R. Bras. Zootec., v.33, n.5, p.1181-1191, 2004 
ileal aparente dos aminoácidos, mostrados na Tabela 4, não se assemelham aos propostos por RhônePoulenc (1993), entretanto, a literatura refere-se a coeficientes médios, não fazendo distinção quanto ao conteúdo de proteína bruta da farinha de carne e ossos.

Além disso, as farinhas de carne e ossos 1 e 2, com 33,53 e $35,72 \%$ de proteína bruta, apresentaram menores coeficientes de digestibilidade ileal aparente da lisina, de 54,87 e 56,69\%, respectivamente. Valor semelhante foi encontrado por Serrano (1989), que, avaliando a digestibilidade ileal aparente de alimentos, utilizando suínos machos castrados anastomosados, com peso médio inicial de $31,34 \mathrm{~kg}$, obteve coeficiente de digestibilidade ileal aparente da lisina de 57,16\%, para farinha de carne e ossos com 35,74\% de proteína bruta. SegundoBrugalli (1996), a reduçãoda digestibilidade da farinha de carne e ossos pode ser atribuída à alta concentração de minerais nesse alimento.

De acordo com Nelson et al. (1996), a digestibilidade dos aminoácidos é afetada pelo excesso de cátions na dieta.

O coeficiente de digestibilidade ileal aparente da lisina, observado para a farinha de carne e ossos 6 , com $52,43 \%$ de proteína bruta, assemelha-se aos coeficientes de 74,9 e $74,0 \%$ propostos por ITCF \& Eurolisine (1995) e pelo NRC (1998), para farinhas de carne e ossos com 50,70 e 51,50\% de proteína bruta, respectivamente. Por outro lado, os coeficientes de digestibilidade ileal aparentes, obtidos para a metionina e treonina, foram superiores aos coeficientes de $78,7 \%$ para a metionina e $72,3 \%$ para a treonina, apresentados pelo ITCF \& Eurolisine (1995), da mesma forma que os valores obtidos foram superiores aos 79,00 e 70,00\%, apresentados pelo NRC (1998), para a metionina e treonina, respectivamente, para o mesmo grupo protéico de farinhas de carne e ossos.

Knabe et al. (1989), avaliando a digestibilidade ileal aparente do nitrogênio e aminoácidos essenciais em suínos, utilizando nove diferentes partidas de farinha de carne e ossos, observaram variação de 57,00 a 75,00\% no coeficiente de digestibilidade ileal aparente do nitrogênio e de 73,00 a $86,00 \%$ e de 35,00 a $65,00 \%$ nos coeficientes de digestibilidade ileal aparente da arginina e do triptofano, respectivamente.

As diferenças entre os coeficientes de digestibilidade ileal aparente dos aminoácidos da farinha de carne e ossos podem ser atribuídas à variação da matéria-prima utilizada, pois, segundo Brasil (1951), com frequiência encontram-se, na com- posição da farinha de carne e ossos, materiais como couro, pêlos e outros. No entanto, Batterham et al. (1986) afirmaram que a baixa qualidade protéica da farinha de carne e ossos pode ser atribuída à presença de colágeno, ossos e tecidos diferenciados, pois algumas proteínas, em estado natural, são apenas parcialmente digestíveis, em decorrência de ligações covalentes entre cadeias polipeptídicas, comoé o caso do colágeno, da elastina e da queratina. Segundo Cheftel et al. (1989), no caso do colágeno, a natureza das ligações covalentes é variável, e os resíduos de desmosina presentes nesta proteína proporcionam a ligação de quatro moléculas de lisina, ressaltando-se que já foram identificadas ligações covalentes isopeptídicas do tipo e-N-(g-glutamil)-lisil e e-N-(b-aspartil)-lisil. Além disso, Rhöne-Poulenc (1993) descreveu que a farinha de carne e ossos e a farinha de penas apresentou as maiores variabilidades dos coeficientes de digestibilidade de aminoácidos.

Entre os aminoácidos essenciais, a arginina apresentou alto coeficiente de digestibilidade ileal aparente de aminoácidos, em todas as farinhas de carne e ossos estudadas, corroborando os resultados obtidos por Knabe et al. (1989) e Serrano (1989). Pode-se notar que a cistina foi o aminoácido que apresentou os menores coeficientes de digestibilidade ileal aparente, entre as seis diferentes partidas de farinhas de carne e ossos, sendo inferiores ao coeficiente de 55\% apresentado pelo NRC (1998). No entanto, Jorgensen et al. (1984) encontraram um valor de $10,5 \%$ da digestibilidade ileal aparente da cisteína para a farinha de carne e ossos.

Os coeficientes médios de digestibilidade ileal verdadeira dos aminoácidos essenciais e não-essenciais, das diferentes farinhas de carne e ossos estudadas, estão apresentados na Tabela 5. Pode-se observar grande variação entre os coeficientes de digestibilidade ileal verdadeira, assim como os valores obtidos para os coeficientes de digestibilidade ileal aparente.

A média das diferenças em percentual em relação aos coeficientes de digestibilidade ileal aparentes (Tabela 4) e verdadeiros (Tabela 5), referentes às seis diferentes partidas de farinha de carne e ossos, observados para a lisina, metionina e treonina, foram de 2,$69 ; 1,49$ e $4,05 \%$ e, portanto, inferiores às apresentadas por Rhöne-Poulenc (1993), de 5,06; 4,93 e $9,21 \%$, respectivamente, embora com perfil de aminoácidos semelhante. As diferenças observadas para a lisina e treonina, por sua vez, foram superiores

\section{R. Bras. Zootec., v.33, n.5, p.1181-1191, 2004}


às diferenças médias observadas por Serrano (1989), para as farinhas de carne e ossos estudadas, que foram de 1,59 e 2,01\%, respectivamente. Entretanto, a diferença obtida para metionina, no presente estudo, mostrou-se inferior à encontrada pelos autores $(3,07 \%)$. Essas divergências entre as diferenças dos coeficientes de digestibilidade ileal aparentes e verdadeiros dos aminoácidos estão relacionadas, segundo Caine (1997), a vários fatores que podem influenciar a perda endógena.
Os coeficientes de digestibilidade ileal verdadeira observados para a lisina, no caso das farinhas de carne e ossos 1 e 2, foram semelhantes ao verificado por Serrano (1989), que obteve digestibilidade ileal verdadeira de $58,25 \%$, ao estudar uma farinha de carne e ossos com $35,74 \%$ de proteína bruta. Avaliando outra amostra de farinha de carne e ossos $(46,98 \%$ de proteína), esse autor obteve coeficiente de digestibilidade ileal verdadeira da lisina de $66,81 \%$, que foi próximo ao encontrado no presente estudo

Tabela 4 - Coeficientes de digestibilidade ileal aparente dos aminoácidos das diferentes farinhas de carne e ossos 1

Table 4 - Aparent ileal digestibility coefficients of amino acids from different meat and bone meals ${ }^{1}$

\begin{tabular}{|c|c|c|c|c|c|c|c|}
\hline & \multicolumn{6}{|c|}{$\begin{array}{c}\text { Farinhas de carne e ossos } \\
\text { Meat and bone meals }\end{array}$} & \multirow[b]{2}{*}{$\mathrm{CV}$} \\
\hline & 1 & 2 & 3 & 4 & 5 & 6 & \\
\hline$\overline{\mathrm{PB}}$ & $63,42^{b}$ & $63,93^{b}$ & $70,86^{\mathrm{b}}$ & $78,24^{\mathrm{a}}$ & $67,66^{b}$ & $83,74^{\mathrm{a}}$ & 5,65 \\
\hline $\begin{array}{l}C P \\
\text { Lisina }\end{array}$ & $54,87^{b}$ & $56,69^{b}$ & $62,35^{a b}$ & $73,21^{\mathrm{a}}$ & $66,09^{a b}$ & $74,80^{\mathrm{a}}$ & 10,25 \\
\hline $\begin{array}{l}\text { Lysine } \\
\text { Metionina } \\
\text { Methionine }\end{array}$ & $72,35^{d}$ & $78,51^{b c}$ & $75,12^{\mathrm{cd}}$ & $80,53^{b}$ & $78,75^{b c}$ & $85,46^{\mathrm{a}}$ & 3,20 \\
\hline $\begin{array}{l}\text { Treonina } \\
\text { Threonine }\end{array}$ & $62,62^{\mathrm{c}}$ & $64,84^{\mathrm{c}}$ & $68,09^{b c}$ & $76,75^{a}$ & $70,94^{b}$ & $81,19^{a}$ & 4,35 \\
\hline $\begin{array}{l}\text { Arginina } \\
\text { Arginine }\end{array}$ & $71,31^{\mathrm{c}}$ & $77,30^{\mathrm{bc}}$ & $76,03^{b c}$ & $87,15^{\mathrm{a}}$ & $80,20^{\mathrm{b}}$ & $88,29^{a}$ & 4,13 \\
\hline $\begin{array}{l}\text { Histidina } \\
\text { Histidine }\end{array}$ & $63,96^{d}$ & $72,02^{\mathrm{c}}$ & $72,92^{\mathrm{c}}$ & $78,74^{b}$ & $73,85^{\mathrm{c}}$ & $87,49^{a}$ & 3,91 \\
\hline $\begin{array}{l}\text { Valina } \\
\text { Valine }\end{array}$ & $64,05^{\mathrm{d}}$ & $66,15^{\mathrm{cd}}$ & $70,99^{c}$ & $77,01^{\mathrm{b}}$ & $70,83^{c}$ & $82,35^{a}$ & 4,62 \\
\hline $\begin{array}{l}\text { Isoleucina } \\
\text { Isoleucine }\end{array}$ & $65,75^{\mathrm{c}}$ & $65,69^{\mathrm{c}}$ & $69,00^{b c}$ & $78,91^{a}$ & $71,42^{b}$ & $81,79^{a}$ & 3,93 \\
\hline $\begin{array}{l}\text { Leucina } \\
\text { Leucine }\end{array}$ & $69,04^{\mathrm{c}}$ & $72,05^{\mathrm{c}}$ & $72,02^{\mathrm{c}}$ & $80,49^{a}$ & $76,38^{b}$ & $83,57^{a}$ & 3,21 \\
\hline $\begin{array}{l}\text { Fenilalanina } \\
\text { Phenylalanine }\end{array}$ & $67,63^{d}$ & $70,60^{\mathrm{cd}}$ & $71,92^{\mathrm{cd}}$ & $79,82^{b}$ & $74,81^{\mathrm{c}}$ & $84,72^{\mathrm{a}}$ & 3,69 \\
\hline $\begin{array}{l}\text { Cistina } \\
\text { Cystine }\end{array}$ & $44,29^{\mathrm{a}}$ & $46,35^{\mathrm{a}}$ & $49,48^{\mathrm{a}}$ & $49,26^{\mathrm{a}}$ & $47,86^{\mathrm{a}}$ & $47,96^{\mathrm{a}}$ & 11,12 \\
\hline $\begin{array}{l}\text { Alanina } \\
\text { Alanine }\end{array}$ & $63,16^{\mathrm{d}}$ & $71,43^{c}$ & $74,45^{\mathrm{c}}$ & $82,82^{b}$ & $74,11^{\mathrm{c}}$ & $88,31^{\mathrm{a}}$ & 3,70 \\
\hline $\begin{array}{l}\text { Ac. aspártico } \\
\text { Aspartic acid }\end{array}$ & $61,04^{\mathrm{c}}$ & $61,84^{\mathrm{c}}$ & $68,59^{b}$ & $76,87^{a}$ & $65,54^{b c}$ & $81,73^{a}$ & 4,87 \\
\hline $\begin{array}{l}\text { Ac. glutâmico } \\
\text { Glutamic acid }\end{array}$ & $66,50^{d}$ & $68,64^{\mathrm{cd}}$ & $71,55^{\mathrm{c}}$ & $77,29^{b}$ & $73,19^{b c}$ & $85,22^{a}$ & 3,72 \\
\hline $\begin{array}{l}\text { Glicina } \\
\text { Glycine }\end{array}$ & $68,85^{\mathrm{c}}$ & $77,06^{\mathrm{b}}$ & $76,88^{b}$ & $87,65^{a}$ & $77,95^{b}$ & $92,07^{\mathrm{a}}$ & 4,40 \\
\hline $\begin{array}{l}\text { Serina } \\
\text { Serine }\end{array}$ & $68,28^{c}$ & $71,47^{\mathrm{c}}$ & $71,01^{\mathrm{c}}$ & $79,44^{\mathrm{a}}$ & $75,66^{b}$ & $81,80^{\mathrm{a}}$ & 3,18 \\
\hline $\begin{array}{l}\text { Tirosina } \\
\text { Tyrosine }\end{array}$ & $63,97^{c}$ & $62,19^{c}$ & $68,58^{c}$ & $72,89^{b}$ & $71,98^{\mathrm{b}}$ & $78,79^{a}$ & 5,44 \\
\hline Média ${ }^{2}$ & 64,23 & 67,68 & 69,94 & 77,43 & 71,85 & 81,60 & \\
\hline
\end{tabular}

1 Valores na mesma linha, com letras diferentes, são diferentes $(P<0,05)$ segundo o teste de Stutent Newman Keuls (SNK).

1 Values in the same row, followed by different letters, are different $(P<.05)$ according to Stutent Newman Keuls test (SNK).

2 Média dos coeficientes de digestibilidade ileal aparente dos aminoácidos.

2 Average aparent ileal digestibility coefficients of the amino acids.

\section{R. Bras. Zootec., v.33, n.5, p.1181-1191, 2004}


Tabela 5 - Coeficientes de digestibilidade ileal verdadeira dos aminoácidos das diferentes farinhas de carne e ossos ${ }^{1}$ Table 5 - True ileal digestibility coefficients of amino acids from different meat and bone meals ${ }^{1}$

\begin{tabular}{|c|c|c|c|c|c|c|c|}
\hline & \multicolumn{6}{|c|}{$\begin{array}{c}\text { Farinhas de carne e ossos } \\
\text { Meat and bone meals }\end{array}$} & \multirow[b]{2}{*}{$\mathrm{CV}(\%)$} \\
\hline & 1 & 2 & 3 & 4 & 5 & 6 & \\
\hline $\mathrm{PB}(C P)$ & $65,06^{\mathrm{b}}$ & $65,47^{b}$ & $72,32^{b}$ & $79,62^{\mathrm{a}}$ & $69,06^{\mathrm{b}}$ & $84,81^{\mathrm{a}}$ & 5,54 \\
\hline Lisina (Lysine) & $57,00^{\mathrm{b}}$ & $58,49^{b}$ & $64,17^{a b}$ & $74,74^{\mathrm{a}}$ & $67,64^{\mathrm{ab}}$ & $76,08^{a}$ & 9,99 \\
\hline Metionina (Methionine) & $73,76^{d}$ & $79,63^{b c}$ & $76,36^{\mathrm{cd}}$ & $81,72^{b}$ & $79,81^{b c}$ & $86,39^{a}$ & 3,15 \\
\hline Treonina(Threonine) & $66,26^{c}$ & $67,83^{b c}$ & $71,15^{b c}$ & $79,48^{\mathrm{a}}$ & $73,43^{b}$ & $83,07^{\mathrm{a}}$ & 4,19 \\
\hline Arginina (Arginine) & $71,89^{c}$ & $77,82^{b c}$ & $76,55^{b c}$ & $87,61^{\mathrm{a}}$ & $80,69^{b}$ & $88,68^{a}$ & 4,11 \\
\hline Histidina (Histidine) & $65,53^{d}$ & $73,10^{\mathrm{c}}$ & $74,27^{\mathrm{c}}$ & $79,89^{b}$ & $74,86^{\mathrm{c}}$ & $88,18^{a}$ & 3,86 \\
\hline Valina(Valine) & $66,77^{b}$ & $68,40^{\mathrm{b}}$ & $73,32^{b}$ & $79,12^{\mathrm{a}}$ & $72,75^{b}$ & $83,93^{\mathrm{a}}$ & 4,48 \\
\hline Isoleucina (Isoleucine) & $68,55^{b}$ & $68,12^{b}$ & $71,43^{b}$ & $80,85^{\mathrm{a}}$ & $73,50^{\mathrm{b}}$ & $83,32^{a}$ & 3,81 \\
\hline Leucina (Leucine) & $71,04^{\mathrm{c}}$ & $73,75^{\mathrm{c}}$ & $73,76^{\mathrm{c}}$ & $81,98^{\mathrm{a}}$ & $77,83^{b}$ & $84,64^{\mathrm{a}}$ & 3,14 \\
\hline Fenilalanina (Phenylalanine) & $69,52^{\mathrm{d}}$ & $72,26^{\mathrm{cd}}$ & $73,59^{\mathrm{cd}}$ & $81,39^{b}$ & $76,23^{c}$ & $85,82^{\mathrm{a}}$ & 3,62 \\
\hline Cistina (Cystine) & $52,74^{\mathrm{a}}$ & $52,59^{a}$ & $55,70^{\mathrm{a}}$ & $56,71^{\mathrm{a}}$ & $53,52^{\mathrm{a}}$ & $51,20^{\mathrm{a}}$ & 9,83 \\
\hline Alanina (Alanine) & $64,61^{\mathrm{d}}$ & $72,74^{\mathrm{c}}$ & $75,79^{\mathrm{c}}$ & $84,08^{b}$ & $75,36^{\mathrm{c}}$ & $89,35^{\mathrm{a}}$ & 3,64 \\
\hline Ac.Aspártico (Aspartic ac) & $62,96^{\mathrm{c}}$ & $63,51^{\mathrm{c}}$ & $70,26^{\mathrm{b}}$ & $78,38^{\mathrm{a}}$ & $67,02^{b c}$ & $82,88^{\mathrm{a}}$ & 4,76 \\
\hline Ac.Glutâmico (Glutamic ac) & $67,73^{\mathrm{d}}$ & $69,73^{\mathrm{cd}}$ & $72,62^{\mathrm{cd}}$ & $78,35^{\mathrm{b}}$ & $74,17^{\mathrm{c}}$ & $85,94^{\mathrm{a}}$ & 3,67 \\
\hline Glicina (Glycine) & $69,63^{c}$ & $77,81^{b}$ & $77,61^{\mathrm{b}}$ & $88,32^{\mathrm{a}}$ & $78,70^{\mathrm{b}}$ & $92,70^{\mathrm{a}}$ & 4,36 \\
\hline Serina (Serine) & $69,78^{c}$ & $72,86^{\mathrm{c}}$ & $72,31^{\mathrm{c}}$ & $80,70^{\mathrm{a}}$ & $76,83^{b}$ & $82,74^{\mathrm{a}}$ & 3,13 \\
\hline Tirosina (Tyrosine) & $66,73^{c}$ & $64,43^{c}$ & $70,75^{b c}$ & $75,09^{a b}$ & $73,70^{\mathrm{ab}}$ & $80,07^{a}$ & 5,29 \\
\hline Média $^{2}$ & 66,53 & 69,57 & 71,85 & 79,28 & 73,50 & 82,81 & \\
\hline
\end{tabular}

1 Valores na mesma linha, com letras diferentes, são diferentes $(P<0,05)$ segundo o teste de Stutent Newman Keuls (SNK).

1 Values in the same row, followed by different letters, are different $(P<.05)$ according to Stutent Newman Keuls test (SNK).

2 Média dos coeficientes de digestibilidade ileal verdadeira dos aminoácidos.

2 Average true ileal digestibility coefficients of the amino acids.

para a farinha de carne e ossos 5 , porém com $40,50 \%$ de proteína bruta. O NRC (1998) propõe, para farinha de carne e ossos com $51,50 \%$ de proteína bruta, o coeficiente de digestibilidade ileal verdadeira de $80,00 \%$ para a lisina, que supera o valor obtido para a farinha de carne e ossos 6 (52,43\% de proteína bruta).

Observa-se, nas Tabelas 4 e 5, que houve, em média, diferença entre os coeficientes de digestibilidade em relação às farinhas de carne e ossos 4 e 5, que, no entanto, apresentaram valores semelhantes de proteína bruta $(40,26$ e $40,50 \%$, respectivamente). Estes dados vão de encontro aos apresentados por Afz et al. (2000), que classificam as farinhas de carne e ossos de digestibilidade normal e baixa, apresentando digestibilidade ileal estandarizada para a lisina de 84,00 e $72,00 \%$, respectivamente. A baixa digestibilidade foi atribuída à farinha de carne e ossos com maior conteúdo protéico $(54,7 \%)$ em relação à normal (51,10\%), evidenciando que a composição da matéria-prima das farinhas de carne e ossos não é o único fator que pode influenciar os resultados de digestibilidade ileal de aminoácidos para suínos.
Knabe et al. (1989) relataram que, além da matéria-prima utilizada, o processamento térmico e, ou, a combinação entre estes dois fatores são os grandes responsáveis pelas diferenças entre os coeficientes de digestibilidade ileal de diferentes farinhas de carne e ossos.

Dessa forma, as diferenças entre os valores de digestibilidade ileal de aminoácidos para suínos, de diferentes partidas de farinhas de carne e ossos, podem ser atribuídas também ao processamento térmico a que foram submetidas. Knabe et al. (1989) observaram menores coeficientes de digestibilidade ileal aparente para as farinhas de carne e ossos submetidas a maiores temperaturas durante o processamento. Bjarnason \& Carpenter (1970) constataram que o grupo carboxílico livre do ácido aspártico e ácido glutâmico da proteína pode ligar-se ao grupo amino-livre ( $\mathrm{NH}_{2}$-terminal) da mesma proteína ou de outra proteína, havendo eliminação de amônia; essa interação pode ser acelerada pelo calor, alterando a digestão das proteínas, semelhantemente ao que acontece com a reação de Maillard. 
A farinha de carne e ossos, como já mencionado, é uma fonte protéica submetida ao tratamento térmico durante o processamento, e aminoácidos como lisina, metionina, cistina e triptofano podem reagir com compostos redutores presentes na farinha de carne e ossos, durante o processamento. No caso da lisina, os derivados deoxiketosil (compostos de Amadori) formados podem se reverter à lisina durante a hidrólise ácida submetida na análise de aminoácidos, o que pode superestimar a lisina presente na farinha de carne e ossos e prejudicar a determinação do coeficiente de digestibilidade (Donkoh et al., 1994), que pode explicar, em parte, os baixos coeficientes de digestibilidade obtidos para a lisina em relação à maioria dos aminoácidos avaliados. Além disso, pode ocorrer a formação de lisinoalanina, causada pelo tratamento térmico, o que reduz o valor nutricional e biológico das proteínas (Piva et al., 2001).

Nas Tabelas 6 e 7, são apresentados os valores de aminoácidos digestíveis aparentes e verdadeiros.

O conteúdo de aminoácidos digestíveis, aparentes e verdadeiros, em média, apresentou relação diretamente proporcional ao conteúdo de proteína bruta das farinhas de carne e ossos, apresentada também por Serrano (1989) e Rostagno et al. (2000), para farinhas de carne e ossos com diferentes conteúdos protéicos.

Em razão da variabilidade na composição nutricional das farinhas de carne e ossos, torna-se necessário utilizar valores de aminoácidos digestíveis, quando este alimento estiver presente na formulação de dietas, proporcionando maior precisão na formulação.

Tabela 6 - Composição em aminoácidos digestíveis aparentes, em porcentagem da matéria natural Table 6 - Apparent digestible amino acid composition, as fed basis

\begin{tabular}{|c|c|c|c|c|c|c|}
\hline \multirow{2}{*}{$\begin{array}{l}\text { Aminoácidos (\%) } \\
\text { Amino acids (\%) }\end{array}$} & \multicolumn{6}{|c|}{$\begin{array}{c}\text { Farinhas de carne e ossos } \\
\text { Meat and bone meals }\end{array}$} \\
\hline & 1 & 2 & 3 & 4 & 5 & 6 \\
\hline Lisina (Lysine) & 0,78 & 0,95 & 1,05 & 1,46 & 1,33 & 1,77 \\
\hline Metionina (Methionine) & 0,29 & 0,40 & 0,35 & 0,39 & 0,44 & 0,52 \\
\hline Treonina (Threonine) & 0,51 & 0,64 & 0,67 & 0,84 & 0,87 & 1,28 \\
\hline Arginina (Arginine) & 1,80 & 2,19 & 2,14 & 2,79 & 2,49 & 3,29 \\
\hline Histidina (Histidine) & 0,25 & 0,41 & 0,34 & 0,43 & 0,47 & 0,78 \\
\hline Valina(Valine) & 0,71 & 0,89 & 0,92 & 1,11 & 1,15 & 1,57 \\
\hline Isoleucina (Isoleucine) & 0,45 & 0,52 & 0,55 & 0,78 & 0,67 & 1,02 \\
\hline Leucina (Leucine) & 1,02 & 1,25 & 1,24 & 1,61 & 1,61 & 2,31 \\
\hline Fenilalalanina (Phenylalanine) & 0,61 & 0,73 & 0,75 & 0,88 & 0,93 & 1,33 \\
\hline Cistina (Cystine) & 0,06 & 0,09 & 0,10 & 0,08 & 0,11 & 0,18 \\
\hline Alanina (Alanine) & 1,76 & 2,22 & 2,27 & 2,70 & 2,48 & 3,41 \\
\hline Ac. aspártico (Aspartic acid) & 1,29 & 1,50 & 1,67 & 2,08 & 1,85 & 2,87 \\
\hline Ac. glutâmico (Glutamic acid) & 2,35 & 2,75 & 2,93 & 3,22 & 3,34 & 5,15 \\
\hline Glicina (Glycine) & 4,17 & 4,87 & 4,99 & 6,20 & 5,07 & 6,81 \\
\hline Serina (Serine) & 0,81 & 0,92 & 0,99 & 1,13 & 1,19 & 1,55 \\
\hline Tirosina (Tyrosine) & 0,24 & 0,28 & 0,33 & 0,34 & 0,44 & 0,62 \\
\hline
\end{tabular}


Tabela 7 - Composição em aminoácidos digestíveis verdadeiros, em porcentagem da matéria natural

Table 7 - True digestible amino acid composition, as fed basis

\begin{tabular}{|c|c|c|c|c|c|c|}
\hline \multirow{3}{*}{$\begin{array}{l}\text { Aminoácidos (\%) } \\
\text { Amino acids }(\%)\end{array}$} & \multicolumn{6}{|c|}{ Farinhas de carne e ossos } \\
\hline & \multicolumn{6}{|c|}{ Meat and bone meals } \\
\hline & 1 & 2 & 3 & 4 & 5 & 6 \\
\hline Lisina & 0,81 & 0,98 & 1,08 & 1,49 & 1,36 & 1,80 \\
\hline $\begin{array}{l}\text { Lysine } \\
\text { Metionina }\end{array}$ & 0,30 & 0,40 & 0,35 & 0,39 & 0,44 & 0,53 \\
\hline $\begin{array}{l}\text { Methionine } \\
\text { Treonina }\end{array}$ & 0,54 & 0,67 & 0,70 & 0,87 & 0,90 & 1,31 \\
\hline Threonine & & & & & & \\
\hline Arginina & 1,81 & 2,21 & 2,16 & 2,81 & 2,51 & 3,30 \\
\hline $\begin{array}{l}\text { Arginine } \\
\text { Histidina }\end{array}$ & 0,26 & 0,42 & 0,34 & 0,44 & 0,48 & 0,79 \\
\hline Histidine & & & & & & \\
\hline Valina & 0,74 & 0,92 & 0,95 & 1,14 & 1,18 & 1,60 \\
\hline Valine & & & & & & \\
\hline Isoleucina & 0,47 & 0,53 & 0,57 & 0,80 & 0,69 & 1,03 \\
\hline Isoleucine & & & & & & \\
\hline $\begin{array}{l}\text { Leucina } \\
\text { Leucine }\end{array}$ & 1,05 & 1,28 & 1,27 & 1,64 & 1,64 & 2,34 \\
\hline $\begin{array}{l}\text { Fenilalalanina } \\
\text { Phenvlalanine }\end{array}$ & 0,63 & 0,75 & 0,76 & 0,90 & 0,95 & 1,34 \\
\hline $\begin{array}{l}\text { Cistina } \\
\text { Cystine }\end{array}$ & 0,08 & 0,10 & 0,11 & 0,09 & 0,12 & 0,19 \\
\hline $\begin{array}{l}\text { Alanina } \\
\text { Alanine }\end{array}$ & 1,80 & 2,26 & 2,31 & 2,75 & 2,52 & 3,45 \\
\hline Ac. aspártico & 1,33 & 1,54 & 1,71 & 2,12 & 1,90 & 2,91 \\
\hline Aspartic acid & & & & & & \\
\hline $\begin{array}{l}\text { Ac. glutâmico } \\
\text { Glutamic acid }\end{array}$ & 2,40 & 2,79 & 2,98 & 3,26 & 3,39 & 5,19 \\
\hline Glicina & 4,22 & 4,92 & 5,04 & 6,25 & 5,12 & 6,85 \\
\hline $\begin{array}{l}\text { Glycine } \\
\text { Serina }\end{array}$ & 0,83 & 0,94 & 1,01 & 1,15 & 1,21 & 1,57 \\
\hline $\begin{array}{l}\text { Serine } \\
\text { Tirosina } \\
\text { Tyrosine }\end{array}$ & 0,25 & 0,29 & 0,34 & 0,35 & 0,45 & 0,63 \\
\hline
\end{tabular}

\section{Conclusões}

As farinhas de carne e ossos estudadas apresentaram grande variação, entre as diferentes amostras, em relação aos coeficientes de digestibilidade ileal aparentes e verdadeiros dos aminoácidos.

\section{Literatura Citada}

AFZ, AJINOMOTO EUROLYSINE, AVENTIS ANIMAL NUTRITION, INRA, ITCF. Digestibilidade ileal estandarizada de aminoácidos em ingredientes para rações de suínos (Ami Pig). 2000. 44p

ALBINO, L.F.T.; SILVA, M.A. Valores nutritivos de alimentos para aves e suínos determinados no Brasil. In: SIMPÓSIO INTERNACIONAL SOBRE EXIGÊNCIAS NUTRICIONAIS DE AVES E SUÍNOS, 1996, Viçosa, MG. Anais... Viçosa, MG: Universidade Federal de Viçosa, 1996. p.303-318.
BATTERHAM, E.S.; LOWE, R.F.; DARNELL, R.E. Availability of lysine in meat meal, meat and bone meal and blood meal as determined by slope ratio assay with growing pigs, rats and chicks and by chemical techniques. British Journal Nutrition, v.55, p.427-440, 1986.

BELLAVER, C. Estimation of amino acio digestibility and its usefulness in swine feed formulation. Urbana Champaign: University of Illinois, 1989. 99p. Thesis (PhD - Animal Science) - University of Illinois, 1989.

BERK, A.; SCHULZ, E. Investigations into the digestibility of meat meals in pigs. Animal Research Development, v.41, p.74-85, 1995.

BJARNASON, J.; CARPENTER, K.J. M echanism of heat damage in proteins, 2. Chemical changes in pure protein. British Journal Nutrition, v.24, p.313-329, 1970.

BRASIL. Decreto no 29.651, de 8 de julho de 1951. Aprova o Regulamento de Inspeção industrial e sanitária de Produtos de Origem Animal. RIISPOA, 1951.

BRUGALLI, I. Efeito da granulometria na biodisponibilidade de fósforo e nos valores energéticos da farinha de carne 
e ossos e exigência nutricional de fósforo para pintos de corte. Viçosa, MG: Universidade Federal de Viçosa, 1996. 83p. Dissertação (Mestrado em Zootecnia) - Universidade Federal de Viçosa, 1996.

CAINE, W.R. Ileal recovery of endogenous aminoacids in pigs. Wageningen: Netherland, 1997. 169p. (PhD Thesis). Graf. Serv. Cent., Wagningen, 1997.

CHEFTEL, J.C.; CUQ, J.L.; LORIENT, D. Proteínas alimentarias - Bioquímica, propriedades funcionales, valor nutricional y modificaciones químicas. Zaragoza: Acribia, 1989. 345p.

DONKOH, A.; MOUGHAN, P.J.; SMITH, W.C. Comparison of the slaughter method and simple T-piece cannulation of the terminal ileum for determining ileal amino acid digestibility in meat and bone meal for the growing pig. Animal Feed Science Technology, v.49, p.43-56, 1994.

JOHNSON, M.L.; PARSONS, C.M.; FAHEY, G.C. Effects of special raw material source, ash content and processing temperature on amino acid digestibility of animal by-product meals by cecectomized roosters and ileally cannulated dogs. Journal of Animal Science, v.76, n.4, p.1112-1121, 1998.

JORGENSEN, H.; SAUER, W.C.; THACKER, P.A. Amino acid availabilities in soybean meal, sunflower meal, fish meal and meat and bone meal fed to growing pigs. Journal of Animal Science, v.58, n.4, p.926-934, 1984.

ITCF, EUROLYSINE. Ileal digestibility of amino acids in feedstuffs for pigs. Paris: ITCF, 1995. 53p.

KNABE, D.A.; LA RUE, E.J.; GREGG, E.J. Apparent digestibility of nitrogen and amino acids in protein feedstuffs by growing pigs. Journal of Animal Science, v.67, p.441458, 1989.

LAPLACE, J.P. Amino acid availability in pig feeding. In: WORLD CONGRESS OF ANIMAL FEEDING, 1986, Madrid. Proceedings... Madrid: 1986. v.9, p.109-129.

MINISTÉRIO DA AGRICULTURA PECUÁRIA E ABASTECIMENTO - MAPA. Normas e padrões de nutrição e alimentação animal. Revisão. Curitiba-PR. 1996. 145p.

NATIONAL RESEARCH COUNCIL - NRC. Nutrients requirement of swine. 10.ed. Washington, D.C.: National Academic Press, 1998. 189p.

NELSON, T.S.; KIRBY, L.K.; JOHNSON, Z.B. The effect of altering the cation-anion content with calcium and phosphorus on the digestion of dry matter and amino acids and energy utilization. Poultry Science, v.60, p.786-789, 1996.

PARSONS, C.M.; CASTANON, F.; HAN, Y. Protein and amino acid quality of meat and bone meal. Poultry Science, v.76, p.361-368, 1997.

PIVA, G.; MOSCHINI, M.; FIORENTINI, L. et al. Effect of temperature, pressure and alkaline treatments on meat meal quality. Animal Feed Science and Technology, v.89, p.59-68, 2001.
POZZA, P.C. Valor energético e digestibilidade ileal de aminoácidos de farinha de carne e ossos e de farinha de vísceras para suínos. Viçosa, MG: Universidade Federal de Viçosa, 2001. 79p. Dissertação (Doutorado em Zootecnia) Universidade Federal de Viçosa, 2001.

RHÔNE POULENC. Rhodimet feed formulation guide. 6.ed. France: Rhône-Poulenc Animal Nutrition, 1993. 39p.

ROSTAGNO, H.S.; FEATHERSTON, W.R. Estudos de métodos para determinação de disponibilidade de aminoácidos. Revista da Sociedade Brasileira de Zootecnia, v.6, p.64-75, 1977.

ROSTAGNO, H.S.; SILVA, D.J.; COSTA, P.M.A. et al. Composição de alimentos e exigências nutricionais de aves e suínos (tabelas brasileiras). Viçosa, MG: Universidade Federal de Viçosa, 1991. 61p.

ROSTAGNO, H.S.; ALBINO, L.F.T.; DONZELE, J.L. et al. Tabelas brasileiras para aves e suínos: composição de alimentos e exigências nutricionais. Viçosa, MG: Universidade Federal de Viçosa. 1.ed. 2000. 141p.

SAUER, W.C.; OZIMEK, L. Digestibility of amino acid in swine: results and their practical applications. A review. Livestock Production Science, v.15, p.367-388, 1986.

SEERLEY, R.W. Major feedstuffs used in swine diets. In: MILLER, E.R.; ULLREY, D.E.; LEWIS, A.J. (Eds.) Swine nutrition. Butterworth-Heinemann, 1991. p.509-516.

SERRANO, V.O.S. Digestibilidade dos aminoácidos de suplementos protéicos em suínos, submetidos ou não a anastomose íleo-retal. Viçosa, MG: Universidade Federal de Viçosa, 1989. 55p. Dissertação (Mestrado em Zootecnia) Universidade Federal de Viçosa, 1989.

SILVA, D.J. Análise de alimentos (Métodos químicos e biológicos). Viçosa, MG: Universidade Federal de Viçosa, 1990. 160p.

UNIVERSIDADE FEDERAL DE VIÇOSA - UFV. Manual de utilização do programa SAEG (Sistema para análises estatísticas e genéticas). Viçosa, MG: Universidade Federal de Viçosa, 1999. 59p.

VIEITES, F.M. Valores energéticos e de aminoácidos digestíveis de farinhas de carne e ossos para aves. Viçosa, MG: Universidade Federal de Viçosa, 2000. 75 p. Dissertação (Mestrado em Zootecnia) - Universidade Federal de Viçosa, 2000. 